\title{
Structure Elucidation of Fungal Beauveriolide III, a Novel Inhibitor of Lipid Droplet Formation in Mouse Macrophages
}

\author{
IChiJi Namatame, Hiroshi Tomoda, Noriko Tabata, Shuyi Si \\ and SATOSHI OMURA* \\ Graduate School of Pharmaceutical Sciences, Kitasato University, and \\ Research Center for Biological Function, The Kitasato Institute, \\ Shirokane, Minato-ku, Tokyo 108-8642, Japan
}

(Received for publication October 12, 1998)

\begin{abstract}
The structure of fungal beauveriolide III, an inhibitor of lipid droplet formation in mouse macrophages, was elucidated to be cyclo-[(3S,4S)-3-hydroxy-4-methyloctanoyl-Lphenylalanyl-L-alanyl-D-allo-isoleucyl] by spectral analyses and chemical degradation.
\end{abstract}

During our screen for microbial-based inhibitors of macrophage-derived foam cell formation, a novel cyclodepsipeptide named beauveriolide III was isolated along with a known compound beauveriolide $\mathrm{I}^{1)}$ from the fermentation broth of Beauveria sp. FO-6979 ${ }^{2}$ (Fig. 1). It was suggested that they are structurally related ${ }^{2}$. In this report, the structure elucidation of beauveriolide III is described.

\section{Materials and Methods}

\section{Materials}

Beauveriolides I and III were isolated from the culture broth of Beauveria sp. FO-6979 as described in the preceding paper $^{2}$.

\section{General Experimental Procedures}

UV spectra were recorded on a Shimadzu UV-200S spectrophotometer. IR spectra were recorded on a Horiba FT-210 infrared spectrometer. Melting point was measured with a Yanaco micromelting point apparatus. Optical rotations were obtained with a JASCO DIP-370 digital polarimeter. FAB-MS spectra were recorded on a JMS-DX300 mass spectrometer, and HRFAB-MS spectra were recorded on a JMS-AX505 HA mass spectrometer. The various NMR spectra were obtained on a Varian XL-400 spectrometer.

\section{Acid Hydrolysis}

Beauveriolide III $(7.0 \mathrm{mg})$ was degraded in a gas phase of $6 \mathrm{M} \mathrm{HCl}(990 \mu \mathrm{l})$ and phenol $(10 \mu \mathrm{l})$ at $150^{\circ} \mathrm{C}$ for 4 hours using the PICO - TAG work station (Waters). The degradation products were dissolved in acidic $\mathrm{H}_{2} \mathrm{O}(\mathrm{pH}$ $3,2.0 \mathrm{ml})$ and extracted with diethyl ether $(2.0 \mathrm{ml} \times 3$ times). To determine the amino acid constituents, the aqueous layer $(4.0 \mu \mathrm{l})$ was analyzed by HPLC (SUMICHIRAL OA-5000, $4.6 \times 150 \mathrm{~mm}$, UV at $254 \mathrm{~nm}$, $1.0 \mathrm{ml} / \mathrm{minute}$ ). HPLC was carried out using Shimadzu (LC-7A) Systems. Using $1 \mathrm{~mm}$ aq $\mathrm{CuSO}_{4}$ as a solvent

Fig. 1. Structures of beauveriolides I and III.

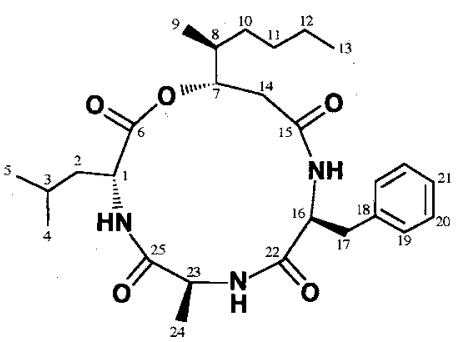

Beauveriolide I

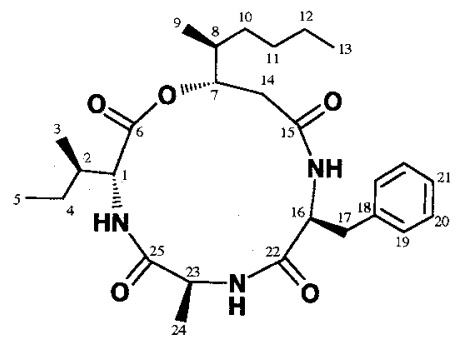

Beauveriolide III 
Fig. 2. Separation of alanine, phenylalanine, isoleucine by HPLC column, SUMICHIRAL OA-5000 $(4.6 \times 150 \mathrm{~mm})$ UV at $254 \mathrm{~nm}$; $1 \mathrm{ml} /$ minute

A, solvent $1 \mathrm{~mm}$ aq $\mathrm{CuSO}_{4}$ for $\mathrm{L}$ - and D-alanine. $\mathrm{B}$, solvent $15 \%$ methanol in $2 \mathrm{mM}$ aq $\mathrm{CuSO}_{4}$ for $\mathrm{L}-$, D-allo-isoleucine, L- and D-isoleucine. C, solvent $30 \%$ methanol in $2 \mathrm{~mm}$ aq $\mathrm{CuSO}_{4}$ for $\mathrm{L}-$ and D-phenylalanine.

Each amino acid $(5 \mu \mathrm{g})$ was injected.

A

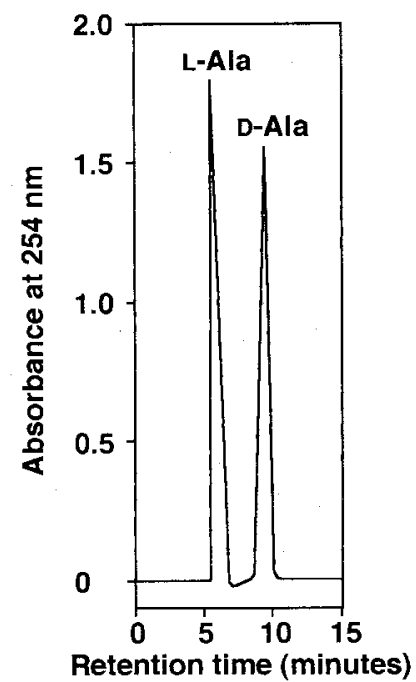

B

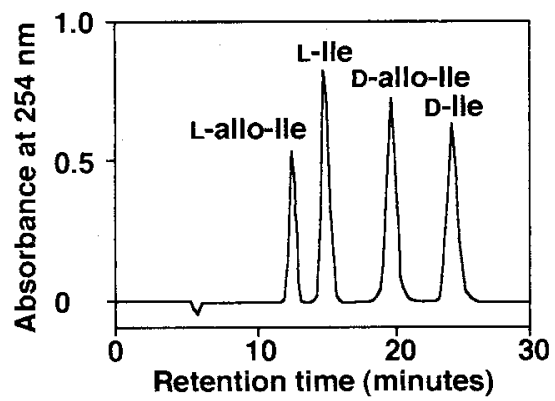

C

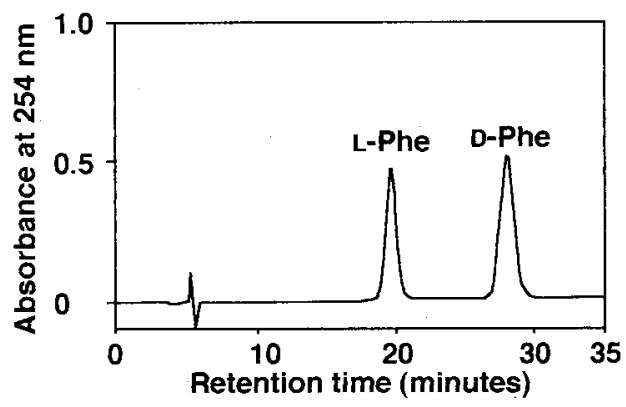

for HPLC, L- and D-alanine were eluted as peaks with retention times of 6.0 and 10.0 minutes, respectively. Using $15 \%$ methanol in $2 \mathrm{~mm}$ aq $\mathrm{CuSO}_{4}, \mathrm{~L}-$, D-alloisoleucine, $\mathrm{L}$ - and $\mathrm{D}$-isoleucine were eluted as peaks with retention times of $13.0,20.0,15.0$ and 24.5 , respectively. Using $30 \%$ methanol in $2 \mathrm{~mm}$ aq $\mathrm{CuSO}_{4}$, L- and D- phenylalanine were eluted as peaks with retention times of 20.0 and 28.0 , respectively (Fig. 2). To determine the stereochemistry of the 3-hydroxy-4-methyl-octanoic acid, the aqueous layer $(700 \mu \mathrm{l})$ was also subjected to a Toyopak SP colunm (Tosoh) to adsorb amino acids. The pass-through fraction containing 3-hydroxy-4-methyloctanoic acid was concentrated in vacuo and the residue $(1.9 \mathrm{mg})$ was methylated with (trimethylsilyl)diazomethane $(2.0 \mathrm{M}$ solution, $100 \mu \mathrm{l})$ (Aldrich) in benzene $(1 \mathrm{ml})$ and methanol $(100 \mu \mathrm{l})$ at room temperature for 3 days. After evaporation, 3-hydroxy-4-methyloctanoate methyl ester $(2.1 \mathrm{mg})$ was obtained.

\section{Results}

Physico-chemical Properties of Beauveriolide III

Physico-chemical properties of beauveriolide III are summarized in Table 1. The data of beauveriolide $I$ is also shown for comparative purpose. Beauveriolides showed the same molecular weight $(\mathrm{m} / \mathrm{z} 487)$ and the same UV maxima at $215 \mathrm{~nm}$. The IR spectrum of beauveriolide III suggested the presence of amide group $\left(3300 \mathrm{~cm}^{-1}\right)$ and four carbonyl groups $(1726,1686,1639$, and $1539 \mathrm{~cm}^{-1}$ ). These data suggested that beauveriolide III is structurally related to beauveriolide I.

\section{Structure of Beauveriolide III}

The molecular formula of beauveriolide III was determined to be $\mathrm{C}_{27} \mathrm{H}_{41} \mathrm{~N}_{3} \mathrm{O}_{5}$ on the basis of HREI-MS measurement $(\mathrm{m} / \mathrm{z}$, found 488.3127 , calcd 488.3124 for $\mathrm{C}_{27} \mathrm{H}_{42} \mathrm{~N}_{3} \mathrm{O}_{5}[\mathrm{M}+\mathrm{H}]^{+}$). The ${ }^{13} \mathrm{C}$ NMR spectrum $\left(\mathrm{CDCl}_{3}-\mathrm{CD}_{3} \mathrm{OD}, 4: 1\right)$ showed 25 resolved peaks corresponding to 27 carbons (Table 2), which were classified into five methyl, six methylene, two methine, three amino methine, one oxy methine, five $s p^{2}$ methine, one $s p^{2}$ quaternary, and four carbonyl carbons by analysis of the DEPT spectra. The ${ }^{1} \mathrm{H}$ NMR spectrum in $\mathrm{CDCl}_{3}-\mathrm{CD}_{3} \mathrm{OD}$ displayed 38 proton signals (Table 2), whereas ${ }^{1} \mathrm{H}$ NMR spectrum in $\mathrm{CDCl}_{3}$ gave additional three proton signals ( $\delta 7.41,6.28$ and 6.25 ), suggesting the presence of three NH protons. These results supported the molecular formula. The connectivity of proton and carbon atoms was confirmed by the HMQC spectrum (Table 2). Analyses of ${ }^{1} \mathrm{H}-{ }^{1} \mathrm{H}$ COSY spectrum revealed the presence of the six partial structures I to VI (Fig. 3). Preliminary analyses of the hydrolysates of beauveriolide III $(6 \mathrm{M} \mathrm{HCl}$ containing $1 \%$ phenol at $115^{\circ} \mathrm{C}$ for 20 hours) by TLC using ninhydrin reagents suggested that the compound contained amino acids. On the basis of these findings, ${ }^{13} \mathrm{C}-{ }^{1} \mathrm{H}$ long-range coupl- 
Table 1. Physico-chemical properties of beauveriolides I and III.

\begin{tabular}{|c|c|c|}
\hline & Beauveriolide I & Beauveriolide III \\
\hline Appearance & white powder & white powder \\
\hline Molecular formula & $\mathrm{C}_{27} \mathrm{H}_{41} \mathrm{~N}_{3} \mathrm{O}_{5}$ & $\mathrm{C}_{27} \mathrm{H}_{41} \mathrm{~N}_{3} \mathrm{O}_{5}$ \\
\hline Molecular weight & 487 & 487 \\
\hline \multicolumn{3}{|l|}{ FAB-MS $(m / s)$} \\
\hline \multirow[t]{2}{*}{ Positive } & $488[\mathrm{M}+\mathrm{H}]^{+}$ & $488[\mathrm{M}+\mathrm{H}]^{+}$ \\
\hline & $510[\mathrm{M}+\mathrm{Na}]^{+}$ & $510|\mathrm{M}+\mathrm{Na}|^{+}$ \\
\hline \multicolumn{3}{|l|}{ HRFAB-MS ( $m /-)$ (positive) } \\
\hline $\mathrm{MF}+\mathrm{H}$ & $\mathrm{C}_{27} \mathrm{H}_{42} \mathrm{~N}_{3} \mathrm{O}_{5}$ & $\mathrm{C}_{27} \mathrm{H}_{42} \mathrm{~N}_{3} \mathrm{O}_{5}$ \\
\hline Calcd: & 488.3124 & 488.3124 \\
\hline Found: & 488.3112 & 488.3127 \\
\hline$[\alpha]_{\mathrm{D}}^{25}\left(\mathrm{CHCl}_{3}-\mathrm{CH}_{3} \mathrm{OH}, 4: 1\right)$ & $-21^{\circ}(c 0.44)$ & $-38^{\circ}(c 0.40)$ \\
\hline$U V \lambda_{\max }^{\left(\mathrm{H}_{3}(\mathrm{OH}\right.} \mathrm{nm}(\varepsilon)$ & $215(27,300)$ & $215(15.800)$ \\
\hline \multirow[t]{2}{*}{$\operatorname{IR} v_{\max }^{\mathrm{KBr}}\left(\mathrm{cm}^{-1}\right)$} & $3298,1724,1684$ & $3300,1726,1686$ \\
\hline & 1641,1535 & 1639,1539 \\
\hline \multirow{5}{*}{$\begin{array}{l}\text { Melting point } \\
\text { Solubility }\end{array}$} & $248-250^{\circ} \mathrm{C}$ & $246-248^{\circ} \mathrm{C}$ \\
\hline & & \\
\hline & $\mathrm{EtOH}, \mathrm{CH}_{3} \mathrm{CN}$ & $\mathrm{EtOH}, \mathrm{CH}_{3} \mathrm{CN}$ \\
\hline & $\mathrm{CH}_{3} \mathrm{OH}, \mathrm{CHCl}_{3}$ & $\mathrm{CH}_{3} \mathrm{OH}, \mathrm{CHCl}_{3}$ \\
\hline & $\mathrm{EtOAc}$ & EtOAc \\
\hline Insoluble & $\mathrm{H}_{2} \mathrm{O}, n$-Hexane & $\mathrm{H}_{2} \mathrm{O}, n$-Hexane \\
\hline
\end{tabular}

Table 2. ${ }^{1} \mathrm{H}$ and ${ }^{13} \mathrm{C}$ NMR chemical shifts of beauveriolides I and III.

\begin{tabular}{|c|c|c|c|c|}
\hline \multirow[b]{2}{*}{$\begin{array}{l}\text { Carbon } \\
\text { No. }\end{array}$} & \multicolumn{2}{|c|}{ Beauveriolide I } & \multicolumn{2}{|c|}{ Beauveriolide III } \\
\hline & $\begin{array}{l}{ }^{13} \mathrm{C} \text { chemical } \\
\text { shifts (ppm) }\end{array}$ & $\begin{array}{l}{ }^{1} \mathrm{H} \text { chemical } \\
\text { shifts (ppm) }\end{array}$ & $\begin{array}{l}{ }^{13} \mathrm{C} \text { chemical } \\
\text { shifts (ppm) }\end{array}$ & $\begin{array}{l}{ }^{\mathrm{H}} \mathrm{H} \text { chemical } \\
\text { shifts }(\mathrm{ppm})^{\mathrm{b}}\end{array}$ \\
\hline $1-\mathrm{NH}$ & & & & \\
\hline $\mathrm{C}-1$ & 53.49 & $4.60(1 \mathrm{H} . \mathrm{t}, J=7.0 \mathrm{~Hz})$ & 59.57 & $4.27(1 \mathrm{H}, \mathrm{d}, J=10.0 \mathrm{~Hz})$ \\
\hline C. -2 & 41.91 & $1.53(2 \mathrm{H}, \mathrm{m})$ & 37.39 & $1.67(1 \mathrm{H}, \mathrm{m})$ \\
\hline$C-3$ & 25.71 & $1.52(1 \mathrm{H}, \mathrm{m})$ & 11.06 & $0.85(3 \mathrm{H}, \mathrm{d}, J=7.0 \mathrm{~Hz})$ \\
\hline C -4 & 22.67 & $0.93(3 \mathrm{H}, \mathrm{d}, J=6.0 \mathrm{~Hz})$ & 26.09 & $\begin{array}{l}1.32(1 \mathrm{H}, \mathrm{m}) \\
1.11(1 \mathrm{H}, \mathrm{m})\end{array}$ \\
\hline$C-5$ & 2257 & $0.91(3 \mathrm{H} d J=6.0 \mathrm{~Hz})$ & 14.80 & $0.86(3 \mathrm{H} . \mathrm{t}, J=7.0 \mathrm{~Hz})$ \\
\hline C. 6 & 170.59 & & 169.70 & \\
\hline$C-7$ & 77.30 & $4.94(1 \mathrm{H}, \mathrm{ddd}, J=10.0,4.5,4.0 \mathrm{~Hz})$ & 76.82 & $4.93(1 \mathrm{H}, \mathrm{ddd}, J=10.0,4.5,4.0 \mathrm{~Hz})$ \\
\hline C 8 & 36.56 & $2.05(1 \mathrm{H}, \mathrm{m})$ & 35.83 & $2.04(1 \mathrm{H}, \mathrm{m})$ \\
\hline $\mathrm{C}-9$ & 15.87 & $0.89(3 \mathrm{H}, \mathrm{d}, J=7.0 \mathrm{~Hz})$ & 15.70 & $0.88(3 \mathrm{H}, \mathrm{d}, J=7.0 \mathrm{~Hz})$ \\
\hline C -10 & 31.44 & $1.40(1 \mathrm{H}, \mathrm{m})$ & 30.73 & $1.36(1 \mathrm{H}, \mathrm{m})$ \\
\hline C- -11 & 30.32 & $1.23(2 \mathrm{H}, \mathrm{m})$ & 29.84 & $1.21(2 \mathrm{H}, \mathrm{m})$ \\
\hline C -12 & 23.65 & $1.27(2 \mathrm{H}, \mathrm{m})$ & 23.21 & $1.20(2 \mathrm{H}, \mathrm{m})$ \\
\hline $\mathrm{C}-13$ & 14.30 & $0.88(3 \mathrm{H}, \mathrm{t}, J=7.0 \mathrm{~Hz})$ & 14.11 & $0.84(3 \mathrm{H}, t, J=7.0 \mathrm{~Hz})$ \\
\hline C. -14 & 36.69 & $\begin{array}{l}2.53(1 \mathrm{H}, \mathrm{dd}, J=14.0,4.5 \mathrm{~Hz}) \\
2.41(1 \mathrm{H}, \mathrm{dd}, J=14.0,10.5 \mathrm{~Hz})\end{array}$ & 36.02 & $\begin{array}{l}2.46(1 \mathrm{H}, \mathrm{dd}, J=14.0,4.5 \mathrm{~Hz}) \\
2.38(1 \mathrm{H}, \mathrm{dd}, J=14.0,10.0 \mathrm{~Hz})\end{array}$ \\
\hline $\begin{array}{l}\mathrm{C}-15 \\
16-\mathrm{NH}\end{array}$ & 173.14 & & 172.46 & \\
\hline C-16 & 57.68 & $4.25(1 \mathrm{H}, \mathrm{dd}, J=9.0 .7 .5 \mathrm{~Hz})$ & 57.15 & $4.19(1 \mathrm{H}, \mathrm{dd}, J=8.5,7.5 \mathrm{~Hz})$ \\
\hline $\mathrm{C}-17$ & 36.51 & $\begin{array}{l}3.04(1 \mathrm{H}, \mathrm{dd}, J=13.5,7.5 \mathrm{~Hz}) \\
2.96(1 \mathrm{Hd}, J=13.5,9.0 \mathrm{~Hz})\end{array}$ & 35.86 & $3.04(1 \mathrm{H}, \mathrm{dd}, J=13.5,7.5 \mathrm{~Hz})$ \\
\hline C- 18 & 137.42 & & 136.65 & \\
\hline$C-19$ & 129.85 & $7.15(2 \mathrm{H}, \mathrm{ddd}, J=8.0,1.5,1.0 \mathrm{~Hz})$ & 129.29 & $7.14(2 \mathrm{H}, \mathrm{ddd}, J=8.0,1.5,1.0 \mathrm{~Hz})$ \\
\hline C. 20 & 129.20 & $7.23(2 \mathrm{H}, \mathrm{ddd}, J=8.0,7.0,1.0 \mathrm{H})$ & 128.77 & $7.23(2 \mathrm{H}, \mathrm{ddd}, J=8.0,7.0,1.0 \mathrm{~Hz})$ \\
\hline C -21 & 127.59 & $7.18(1 \mathrm{H}, \mathrm{dd}, J=7.0,1.5 \mathrm{~Hz})$ & 127.18 & $7.18(1 \mathrm{H}, \mathrm{dd}, J=7.0,1.5 \mathrm{~Hz})$ \\
\hline C-22 & $172.54 *$ & & 171.75 & \\
\hline C. -23 & 50.33 & $3.80(\mathrm{lH}, \mathrm{q}, J=7.0 \mathrm{~Hz})$ & 49.72 & $3.85(1 \mathrm{H}, \mathrm{q}, J=7.0 \mathrm{~Hz})$ \\
\hline C. -24 & 15.33 & $1.20(3 \mathrm{H}, \mathrm{d}, J=7.0 \mathrm{~Hz})$ & 15.05 & $1.22(3 \mathrm{H}, \mathrm{d}, J=7.0 \mathrm{~Hz})$ \\
\hline C -25 & $172.54 *$ & & 171.82 & \\
\hline
\end{tabular}

a) Chemical shifts are shown with reference to $\mathrm{CD}_{3} \mathrm{OD}$ as $49.0 \mathrm{ppm}$. b) Chemical shifts are shown with reference to $\mathrm{CD}_{3} \mathrm{OD}$ as $3.30 \mathrm{ppm}$. ${ }^{*}$ ) The signals were observed as the same chemical shifts. 
Fig. 3. Partial structures I to VI of beauveriolide III.

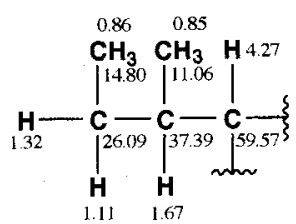

I

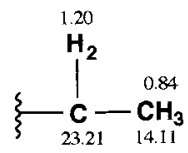

IV

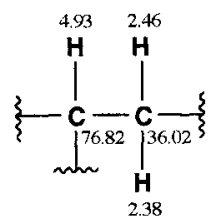

II

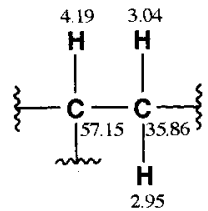

V

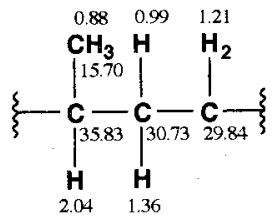

III

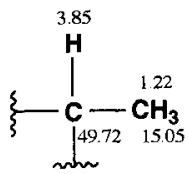

VI ings of ${ }^{2} J$ and ${ }^{3} J$ were measured in the HMBC spectrum (Fig. 4), providing the following structural evidence; Regarding the amino acid components in the structure, 1) the cross peaks from $\mathrm{H}_{3}-24(\delta 1.22)$ to $\mathrm{C}-23(\delta 49.72)$ and $\mathrm{C}-25(\delta$ 171.82), and from $\mathrm{H}-23(\delta 3.85)$ to $\mathrm{C}-25$ showed the presence of an alanine moiety containing the partial structure VI. 2) The long-range couplings from H-1 $(\delta 4.27)$ to $\mathrm{C}-4(\delta 26.09)$, from $\mathrm{H}-2(\delta 1.67)$ to $\mathrm{C}-1$ $(\delta$ 59.57), C-3 ( $\delta 11.06)$ and $\mathrm{C}-5(\delta 14.80)$, from $\mathrm{H}_{3}-3(\delta$ $0.85)$ to $\mathrm{C}-1$ and $\mathrm{C}-4$, from $\mathrm{H}_{2}-4(\delta 1.32,1.11)$ to $\mathrm{C}-1$, $\mathrm{C}-3$ and $\mathrm{C}-5$, and from $\mathrm{H}_{3}-5(\delta 0.86)$ to $\mathrm{C}-4$ showed the presence of an isoleucine moiety containing the partial structure I. 3) The long-range couplings from $\mathrm{H}_{2}-14(\delta$ $2.46,2.38)$ to $\mathrm{C}-7(\delta 76.82)$ and $\mathrm{C}-15(\delta$ 172.46), from $\mathrm{H}-7$ ( $\delta$ 4.93) to $\mathrm{C}-10(\delta 30.73)$ and $\mathrm{C}-15$, from $\mathrm{H}-8(\delta$ $2.04)$ to C-7, from H-9 ( $\delta 0.88)$ to $\mathrm{C}-7$ and $\mathrm{C}-10$, and from $\mathrm{H}_{2}-10(\delta 1.36,0.99)$ to $\mathrm{C}-9(\delta 15.70)$ showed that the partial structure II was attached to the partial structure III. Furthermore, the long-range couplings from $\mathrm{H}_{2}-11(\delta 1.21)$ to $\mathrm{C}-12(\delta 23.21)$ and $\mathrm{C}-13(\delta 14.11)$, from $\mathrm{H}_{2}-12(\delta 1.20)$ to $\mathrm{C}-13$, and from $\mathrm{H}_{3}-13(\delta 0.84)$ to $\mathrm{C}-12$ showed that the partial structure III was attached to the partial structure IV. Therefore, the sequence II-III-IV was indicated to give a 2-hydroxy-3-methyloctanoyl moiety. 4) The long-range couplings from $\mathrm{H}-17$ $(\delta 3.04,2.95)$ to $\mathrm{C}-16(\delta 57.15), \mathrm{C}-18(\delta 136.65), \mathrm{C}-19(\delta$ $129.29)$ and $\mathrm{C}-22(\delta 171.75)$, from $\mathrm{H}-19(\delta 7.14)$ to $\mathrm{C}-17$ $(\delta$ 35.86), C-19, C-20 ( $\delta$ 128.77) and C-21 ( $\delta$ 127.18), tfrom H-20 $(\delta 7.23)$ o C-18 and C-20, and from H-21 $(\delta 7.18)$ to $\mathrm{C}-19$ and $\mathrm{C}-20$ showed the presence of a phenylalanine moiety containing the partial structure $\mathrm{V}$.
Fig. 4. NMR experiments of beauveriolide III.

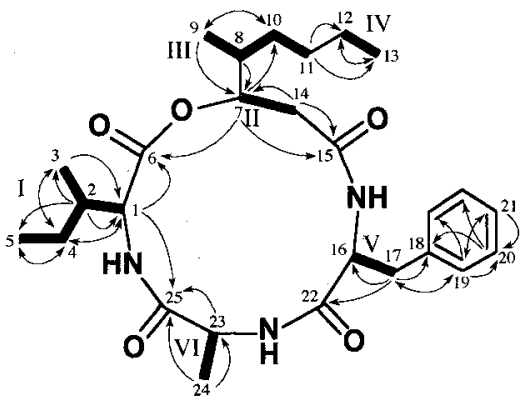

${ }^{1} \mathrm{H}^{-1} \mathrm{H}$ COSY: $, \mathrm{HMBC}: \mathrm{H} \longrightarrow \mathrm{C}$

The sequence of these components was determined as follows; 1) The long-range couplings from $\mathrm{H}-1$ to $\mathrm{C}-25$ and the chemical shift of C-1 ( $\delta$ 59.57) suggested the alanyl-isoleucinyl sequence via amide ester bond. 2) The long-range couplings from $\mathrm{H}-1$ and $\mathrm{H}-7$ to $\mathrm{C}-6(\delta 169.70)$ and the chemical shift of C-7 ( $\delta 76.82)$ suggested that the isoleucine residue was attached to 2-hydroxy-3-methyloctanoylic acid moiety via ester bond. Finally, the cyclic structure was suggested because 1) the two carbons C-16 $(\delta 57.15)$ and $\mathrm{C}-23(\delta 49.72)$ should be bound to an amide nitrogen from the ${ }^{13} \mathrm{C}$ chemical shifts, and 2) the ${ }^{13} \mathrm{C}$ chemical shifts of $\mathrm{C}-15(\delta$ 172.46) and $\mathrm{C}-22(\delta$ 171.75) are assignable for an amide ester carbon. Thus, the phenylalanine moiety should lie between the alanine and 2-hydroxy-3-methyl-octanoyl moieties. This cyclic structure also satisfied the degree of unsaturation, the molecular formula and biosynthesis. From the structure 
Table 3. The structures of beauveriolide type cyclodepsipeptides.

\begin{tabular}{|c|c|c|c|c|c|c|}
\hline \multirow{2}{*}{$\begin{array}{l}R \\
\\
0 \\
1 \\
X_{3} \\
\end{array}$} & \multirow{2}{*}{ 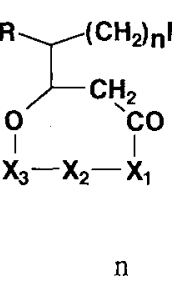 } & \multirow[b]{2}{*}{$\mathrm{R}$} & \multicolumn{3}{|c|}{ Amino acid } & \multirow[b]{2}{*}{ Ref. } \\
\hline & & & $\mathrm{X}_{1}$ & $\mathrm{X}_{2}$ & $\mathrm{X}_{3}$ & \\
\hline Beauveriolide III & 3 & $\mathrm{Me}$ & L-Phe & L-Ala & D-allo-Ile & \\
\hline Beauverolide La & 5 & $\mathrm{Me}$ & L-Phe & L-Ala & D-allo-Ile & 3 \\
\hline Beauveriolide I & 3 & $\mathrm{Me}$ & L-Phe & L-Ala & D-Leu & 1 \\
\hline Beauveriolide II & 5 & $\mathrm{Me}$ & L-Phe & L-Ala & D-Leu & 1 \\
\hline Beauverolide A & 5 & $\mathrm{Me}$ & L-Phe & L-Val & D-Val & 4 \\
\hline Beauverolide D & 3 & $\mathrm{Me}$ & L-Phe & L-Val & D-Val & 4 \\
\hline Beauverolide B & 5 & $\mathrm{Me}$ & L-Val & L-Phe & D-Ile & 4 \\
\hline Beauverolide $\mathrm{E}$ & 3 & $\mathrm{Me}$ & $\mathrm{L}-\mathrm{Val}$ & L-Phe & D-Ile & 4 \\
\hline Beauverolide C & 5 & $\mathrm{Me}$ & L-Phe & L-Phe & D-Ile & 4 \\
\hline Beauverolide F & 3 & $\mathrm{Me}$ & L-Phe & L-Phe & D-Ile & 4,5 \\
\hline Beauverolide $\mathrm{H}$ & 4 & $\mathrm{H}$ & L-Phe & L-Ala & D-Leu & 6 \\
\hline Beauverolide I & 6 & $\mathrm{H}$ & L-Phe & L-Ala & D-Leu & 6 \\
\hline Beauverolide $\mathrm{Ba}^{*}$ ) & 5 & $\mathrm{Me}$ & $\mathrm{L}-\mathrm{Val}$ & L-Phe & D-allo-Hle & 5,7 \\
\hline Beauverolide Ea & 3 & $\mathrm{Me}$ & $\mathrm{L}-\mathrm{Val}$ & L-Phe & D-allo-Ile & 4 \\
\hline Beauverolide $\mathrm{Ca}$ & 5 & $\mathrm{Me}$ & L-Phe & L-Phe & D-allo-Ile & 4,7 \\
\hline Beauverolide Fa & 3 & $\mathrm{Me}$ & L-Phe & L-Phe & D-allo-Ile & 4 \\
\hline Beauverolide Ja & 3 & $\mathrm{Me}$ & L-Trp & L-Phe & D-allo-Ile & 7 \\
\hline Beauverolide $\mathrm{Ka}$ & 5 & $\mathrm{Me}$ & $\mathrm{L}-\mathrm{Trp}$ & L-Phe & D-allo-Ile & 7 \\
\hline
\end{tabular}

*) Also named beauverilide A

as described above, beauveriolide III consists of three amino acids and a hydroxylic acid.

To determine their absolute configuration, beauveriolide III $(7.0 \mathrm{mg})$ was hydrolyzed and the hydrolysate was extracted with diethyl ether. The aqueous layer was analyzed by HPLC using a chiral column. In comparison with peaks of the authentic amino acids (Fig. 2), the main amino acids comprising beauveriolide III were determined to be L-alanine, D-allo-isoleucine and L-phenylalanine, which were detected almost in equimolar quantities. Regarding the stereochemistry of the 3-hydroxy-4-methyl-octanoic acid, the aqueous layer was subjected to a Toyopak SP colunm to adsorb amino acids. The pass-through fraction containing 3-hydroxy4-methyl-octanoic acid was concentrated in vacuo and the residue was treated with diazomethane to give 3-hydroxy-4-methyl-octanoic acid methyl ester $(2.1 \mathrm{mg})$. After the structure was confirmed by NMR, the optical rotation $\left([\alpha]_{\mathrm{D}}^{25}-29^{\circ}, c 0.2\right)$ was compared with that $\left([\alpha]_{\mathrm{D}}^{25}-27^{\circ}, c \quad 0.3\right)$ prepared from beauveriolide $\mathrm{I}$, which was almost identical with the previously reported values ${ }^{1}$. Therefore, the stereochemistry was concluded 
to be $(3 S, 4 S)$-3-hydroxy-4-methyloctanoic acid.

Taken together, the structure of beauveriolide III was elucidated as shown in Fig. 1.

\section{Discussion}

The structure of beauveriolide III including the absolute configurations was elucidated cyclo- $[(3 S, 4 S)-3$ hydroxy-4-methyloctanoyl-L-phenylalanyl-L-alanyl-Dallo-isoleucyl] by spectral analyses and degradation experiments. This type of cyclodepsipeptides, such as beauveriolide, beauverolide and beauverilide, where the common cyclic skeleton is comprised of an hydroxylic acid and three amino acids, are summarized in Table 3. They were reported to be produced by Beauveria sp.

This family shows the structural characteristies as follows; 1) Regarding the part of hydroxylic acid, methylation occured at the $\mathrm{R}$ position for fatty acids of an odd-numbered straight carbon chain (octanoic acid or decanoic acid), while no methylation occured for those of an even-numbered carbon. 2) Hydrophobic amino acids were occupied at the $X_{1}, X_{2}$ and $X_{3}$ positions. Interestingly, $L$-amino acids were introduced at the $\mathrm{X}_{1}$ and $X_{2}$ positions, but D-amino acids were at the $X_{3}$ position. In this sense, the biosynthetic sequence for this type of cyclodepsipeptides might be interesting. Furthermore, the biological activity of this series of cyclodepsipeptides has not been clearly defined. Therefore, it will be interesting to test their inhibitory activity of lipid droplet formation in macrophages.
Acknowledgments

This work was supported by a grant from the "Research for the Future" Program of the Japan Society for the Promotion of Science (JSPS-RFTF96100304) and Japan Keirin Association.

\section{References}

1) Mochizuki, K.; K. Ohomori, H. Tamura, Y. Shizuri, S. NishiYama, E. Miyoshi \& S. Yamamura: The structure of bioactive cyclodepsipeptides, beauveriolides I and II. Metabolites of entomo pathogenic fungi Beauveria sp. Bull. Chem. Soc. Jpn. 66: 3041 3046, 1993

2) Namatame, I.; H. Tomoda, S. Si, Y. Yamaguchi, R. Masuma \& S. ŌMURA: Beauveriolides, specific inhibitors of lipid droplet formation in mouse macrophages, produced by Beauveria sp. FO-6979. J. Antibiotics 52: $1 \sim 6,1999$

3) Jegorov, A.; P. Sedmera, V. Matha, P. Simek, H. ZAHRADNICKOVA, Z. LANDA \& J. Eyal: Beauverolides L and La from Beauveria tenella and Paecilomyces fumosoroseus. Phytochemistry 37: $1301 \sim 1303,1994$

4) Elsworth, J. F. \& J. F. Grove: Cyclodepsipeptides from Beauveria bassiana. Part 2. Beauverolides A to F and their relationship to isarolide. J. Chem. Soc. Perkin Trans I: $1795 \sim 1799,1980$

5) Isogai, A.; M. Kanaoka, H. Matsuda, Y. Hori \& A. SUzUKI: Structure of a new cyclodepsipeptide, beauverilide A from Beauveria bassiana. Agri. Biol. Chem. 42: $1797 \sim 1798,1978$

6) Elsworth, J. F. \& J. F. Grove: Cyclodepsipeptides from Beauveria bassiana. Bals. Part 1. Beauverolides $\mathrm{H}$ and I. J. Chem. Soc. Perkin Trans I: 270 273, 1977

7) Grove, J. F.: Cyclodepsipeptides from Beauveria bassiana. Part 3. The isolation of beauverolides $\mathrm{Ba}, \mathrm{Ca}$, Ja, and Ka. J. Chem. Soc. Perkin Trans I: $2878 \sim 2880$, 1980 